\title{
Does Strength-Based Parenting Predict Academic Achievement? The Mediating Effects of Perseverance and Engagement
}

\author{
Lea E. Waters ${ }^{1} \cdot$ Daniel Loton $^{1} \cdot$ Hayley K. Jach ${ }^{1}$
}

Published online: 9 May 2018

(C) The Author(s) 2018

\begin{abstract}
Strength-based parenting (SBP) is a style of parenting characterized by knowledge and encouragement of a child's unique personality, abilities, talents, and skills (i.e., strengths). Recent studies have demonstrated a unique contribution of SBP, above other parenting styles, in predicting a range of wellbeing indicators in adolescents. Given that wellbeing supports learning, and SBP predicts wellbeing, it is also plausible that adolescents with strength-based parents will have greater academic achievement. At the beginning of term, students from a public secondary school in Australia $\left(N=741, M_{\text {age }}=13.70\right.$, $\mathrm{SD}=1.33 ; 50 \%$ female) completed a self-report survey measuring perceptions of parental style, engagement, and perseverance. Subsequent academic results were obtained 3 months later. SBP predicted higher wellbeing in the form of adolescent engagement and perseverance. SBP also demonstrated a significant effect on academic achievement which was mediated by perseverance, but not engagement. Thus, results supported a model in which adolescents with strength-based parents achieved higher grades via increased perseverance. Results reaffirm the importance of the parent-student link, and dispositional qualities of engagement and perseverance, in predicting educational outcomes such as grades. This study extends positive education research beyond the classroom by demonstrating that positive parenting techniques like SBP can predict student wellbeing and academic achievement.
\end{abstract}

Keywords Strength-based parenting · Academic achievement · Positive psychology · Engagement $\cdot$ Perseverance

Electronic supplementary material The online version of this article (doi:https://doi.org/10.1007/ s10902-018-9983-1) contains supplementary material, which is available to authorized users.

Lea E. Waters

1.waters@unimelb.edu.au

1 Parkville, Melbourne, Australia 


\section{Introduction}

The schooling of children has, for more than a century, been about accomplishment, the boulevard into the world of adult work...but imagine if schools could, without compromising either, teach both the skills of well-being and the skills of achievement. Imagine Positive Education (Seligman et al. 2009, p. 1).

According to Ciarrochi et al. (2016) positive psychology interventions are being used in classrooms all over the world. Certainly, the field of positive education has received significant research attention for well over a decade now (Baker et al. 2009; Parks and Schueller 2014; Waters 2011; Waters et al. 2015). Positive psychology interventions (PPIs) in classrooms have been tested for their impact both on wellbeing (Madden et al. 2011; Proctor et al. 2011b; Oppenheimer et al. 2014; Suldo et al. 2014) and on academic achievement (Durlak et al. 2011; Nidich et al. 2011; Suldo et al. 2011). By and large, the positive education research findings align with the spirit of the opening passage and show that classroom PPIs can help to build both wellbeing and academic achievement, which are theoretically posited to go hand-in-hand (for two recent reviews see Shankland and Rosset 2017; and Waters 2017).

As the field of positive education matures, calls have been made to extend the boundaries of research beyond classroom interventions that target intra-individual change, and take into account the broader social systems and contextual factors that impact a student's wellbeing and achievement (Bronfenbrenner and Ceci 1994; Ciarrochi et al. 2016). Allen et al. (2016) argue that, as a student is nested within many groups, from close relationships in their micro-system (e.g., teachers, peers and parents) to broader connections with the macrosystem (e.g., government regulations of education curriculum and national student testing procedures) there are many factors outside of the classroom that impact student wellbeing.

Amongst other things, a social-ecological approach examines how the interplay between the student's personal qualities (e.g., their levels of engagement and perseverance) and relationships that exist outside of the classroom (e.g., their relationship with the parents) influence achievement. A social-ecological approach can, therefore, be used to investigate naturally occurring relationships that, when better understood, can be used as levers to build student wellbeing and achievement.

Formal positive education programs can often be costly, requiring teacher training and finding room for the lessons in the weekly timetable (Waters 2015a, b). Thus, finding ways to harness the positive influence of existing relationships within students' social-ecological systems will allow all students, regardless of socio-economic background or school funding, to benefit.

In this paper, we consider how a key element in the student's socio-ecological framework-their parents-can positively influence student wellbeing and achievement. Specifically, the purpose of this paper is (a) to consider how the processes of perseverance and engagement predict academic success, and (b) to assess whether a strength-based approach to parenting (i.e., in which parents regularly acknowledge and encourage their child's unique personality, abilities, talents, and skills) predicts adolescents' academic achievement through boosting their levels of perseverance and engagement. 


\subsection{Perseverance, Engagement, and Academic Achievement}

Wellbeing is "the combination of feeling good and functioning well" (Huppert and Johnson 2010, p. 264), and is best characterized as a profile of indicators that fall on the positive side of the mental health spectrum, rather than a single, global, factor (Forgeard et al. 2011; Frey and Stutzer 2010; Keyes 2007; Lerner et al. 2009). Recently, Kern et al. (2016) introduced a multidimensional model of youth wellbeing that consists of five indicators: engagement, perseverance, optimism, connectedness, and happiness. This model is known as the EPOCH model, and is based on Seligman's (2013) multi-dimensional PERMA wellbeing model for adults (positive emotions, engagement, relationships, meaning, and accomplishment). The current study focuses upon the first two elements of the EPOCH model - engagement and perservance — as considerable prior research has linked engagement and perservance to academic achivement.

\subsubsection{Engagement}

Scholars have investigated the structure and impact of student engagement since the 1980s (for a review, see Christenson et al. 2012). As a construct, engagement has undergone multiple permutations, with certain investigators viewing engagement as behaviors such as involvement in school and participation in extracurricular activities (Finn 1989), and others suggesting that engagement is more a mental state, characterized by self-regulation and perceptions of school connectedness (Appleton et al. 2006). The current study adopts a positive psychology approach to engagement and conceptualizes it as a personality trait reflecting levels of absorption, interest, and enjoyment (Kern et al. 2015). At its extreme high end, engagement is identical to a state of flow (Bempechat and Shernoff 2012; Shernoff et al. 2003) while at its extreme low end, engagement reflects apathy (Lamborn et al. 1992b).

It is well established that engagement in school strongly predicts academic achievement (Ainley and Ainley 2011; Appleton et al. 2008; Bandura 1997; Dotterer and Lowe 2011; Dweck 2006; Hughes et al. 2008; Newmann 1992; Singh et al. 2002). For example, results from a 50-year longitudinal study indicated that students who were engaged or intellectually invested in school had a higher level of educational attainment (e.g., a graduate degree versus not completing high school; Clausen 1991). Shernoff and Hoogstra (2001) found that student reports of engagement in high school science class predicted their subsequent choice to study science at university; and also found that interest and enjoyment in math and science predicted the student's academic achievement at university. Empirical research has also shown that flow is associated with academic commitment and achievement throughout the teenage years (Bassi et al. 2007; Csikszentmihalyi et al. 1993; Nakamura 1988). These results indicate that finding ways to increase a student's level of engagement may be a promising conduit to improving school grades.

\subsubsection{Strengths-Based Approaches and Engagement}

Research in positive education has found that encouraging a student to use his/her strengths can lead to higher levels of engagement. Seligman et al. (2009) investigated the effects of a positive psychology intervention on 347 secondary school students where, amongst other exercises, students were taught how to identify their strengths through the Values in Action 
Inventory of Strengths (VIA), a list of 24 character strengths judged to be virtuous (Peterson and Seligman 2004; Csikszentmihalyi and Seligman 2000). Once students had identified their strengths, they were encouraged to use their top-scored strengths frequently and in new ways. At the end of the study, both students and their teachers reported an increase in student engagement at school. At a 6- and 18-month follow-up, teachers continued to rate students who were part of the strengths intervention as higher on strengths related to engagement, such as curiosity and love of learning.

The strengths-engagement link was further corroborated by Madden et al. (2011), who conducted a positive coaching study with primary school students. In one component of the intervention, children were taught to identify their top strengths and were then coached to use these strengths. Student-rated engagement increased significantly at post-test, indicating that strengths training may be one avenue towards increased engagement.

\subsubsection{Perseverance}

The second wellbeing indicator in the current study, perseverance, has been defined by Bloom (1968) as "the amount of time one is willing to spend in learning" (p. 6) and is posited to be a key factor in academic achievement. In the EPOCH model, Kern et al. (2016) define perseverance as the capacity to carry out plans and goals to completion; or in layman's terms, being a "hard worker" (p. 31). This description of perseverance is conceptually aligned with the industriousness aspect of the Big Five personality trait conscientiousness (one of two aspects, the other being orderliness; DeYoung et al. 2007). Trapmann et al. (2007) found that conscientiousness was a strong predictor of academic achievement, as did Komarraju et al. (2011).

Perseverance has also been investigated as one half of the construct grit (the other half being passion) which has been found to predict a range of academic outcomes such as undergraduate grade point average (Duckworth et al. 2007), ranking in a National Spelling Bee (Duckworth et al. 2011) and likelihood to graduate from school (Eskreis-Winkler et al. 2014). Overall, multiple theoretical frameworks and psychological constructs converge to support the notion that perseverance is central to academic achievement.

Studies have demonstrated subsequent increases in engagement following a strengthsbased intervention, showing promise for strengths-based approaches, but there is less evidence available to appraise the modifiability of perseverance. It is important to consider whether change on this personality trait is even possible. Drawing on more general personality research, a number of large-scale, longitudinal studies have shown that individuals become more conscientious over time (Roberts et al. 2006; Robins et al. 2001; Srivastava et al. 2003). Additionally, Hudson and Fraley (2015) found that there was a relationship between those who expressed a desire to change their level of conscientiousness and the actual level of change that was measured. Their study showed that volitional personality change is possible within 16 weeks. Given the strong theoretical alignment between perseverance and one aspect of conscientiousness, it is reasonable to extrapolate from this research that one's level of perseverance is likely a modifiable quality (Srivastava et al. 2003). This is promising for the idea that students can increase their levels of perseverance through intentional action and perseverance-promoting environments and relationships.

Perseverance itself is considered one of the 24 character strengths that comprise the VIA, and thus to the degree that strengths interventions succeed in increasing the use of a student's strengths, it is reasonable to infer that strengths intervention can be used to increase the particular strength of perseverance. Given that using one's strengths is an 


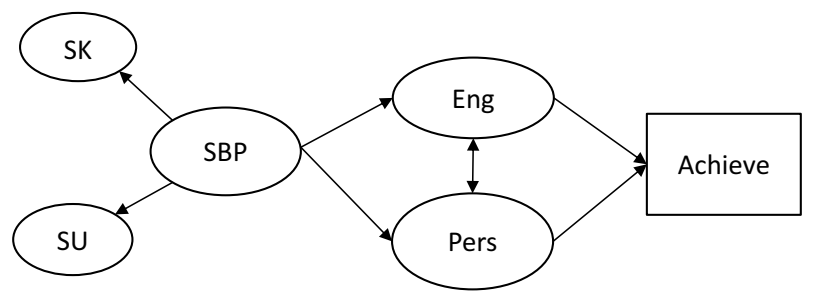

Fig. 1 A depiction of the hypothesized structural equation model. $S K$ Strengths knowledge, $S U$ strengths use, SBP strength-based parenting, Eng engagement, Pers perseverance, Achieve Academic achievement

energizing experience that enhances intrinsic motivation, we also suggest that general strengths intervention may indirectly help students to persist in their goals for longer (Larson and Rusk 2010).

In the strengths literature, there are suggestions that perseverance may play an indirect role in the relationship between strengths use and achievement. For example, strengths use in college students was significantly related to the long term process of goal progress (Linley et al. 2010). However, while there is a theoretically plausible link between strengths use and perseverance, evidence is currently peripheral and the pathway between strengths use and perseverance has not been directly tested in the context of positive education. The current study will address this gap.

\subsubsection{The Relationship Between Engagement and Perseverance}

As outlined in Fig. 1 below, our model posits that engagement and perseverance are distinct but inter-related. In this context, perseverance is distinguished from engagement by a more explicit orientation toward goal completion, but the two constructs can co-exist in complex ways, even across different life circumstances (Della Fave and Massimini 2005). According to Nakamura and Csikszentmihalyi (2014), the state of flow fosters persistence because it is highly psychologically rewarding. The continued effort born from engagement/flow subsequently fosters skill development and eventual mastery and achievement, which further enables flow. Following Nakamura and Csikszentmihalyi's logic, we propose that there is a bidirectional and mutually reinforcing relationship between engagement and perseverance.

\subsection{Parenting and Engagement, Perseverance, and Achievement}

As outlined above, until relatively recently, positive education has focused on classroom interventions as the core way to increase student wellbeing and achievement (Seligman et al. 2009; Waters 2011). Yet, ecological theory suggests student development and behavior is grounded in a series of concentric circles of influence, from the microsystem of immediate interaction between the student and close individuals, through to the mesosystem of interactions between these different microsystems, to the exosystem of structures that occur in the background of an adolescent's life, to the macrosystem which comprises the culture of a given society (Bronfenbrenner 1977; Allen et al. 2016). While the research focus on classroom PPIs involves the student's microsystem, we suggest that positive education research has not sufficiently stepped out to consider the influence of wider concentric circles on student wellbeing and academic achievement. 
Classrooms are certainly a vital component in the ecosystem of a student's life, but family can be considered an equally important element. First, child-parent relationships exist within both the microsphere and mesosphere. Second, parents have an indirect influence on the exosystem and the macrosystem through choosing the school which the child attends. Third, considerable research now exists to show that parental involvement in a student's academic life is a significant predictor of academic achievement (for a recent meta-analysis see Ma et al. 2016; see also Alexander et al. 1997; Battin-Pearson et al. 2000; GonzalezPienda et al. 2002.)

In the current paper, we suggest that a richer understanding of student wellbeing and academic achievement can be made when an ecological approach is taken to positive education by incorporating aspects of the family environment. Specifically, in the case of the current study, we are interested in whether strength-based parenting is related to student levels of engagement, perseverance and academic achievement.

Parents have the power to influence their child's trajectory in a myriad of ways and much research has centered around the academic outcomes of one particular style of parenting, authoritative parenting, in which parents are caring but also set appropriate boundaries for their children (Steinberg et al. 1989; Lamborn et al. 1991; Steinberg et al. 1992). Authoritative parenting is made up of two parental dimensions: (1) responsiveness, which is the degree to which parents respond to the needs of the child, and (2) control, which is the degree to which parents grant autonomy to their children or retain strict control (Baumrind and Damon 1989; Baumrind 1991).

Authoritative parenting is a significant predictor of educational success (Lamborn et al. 1992a). It is also a significant predictor of engagement (Lamborn et al. 1992b) and perseverance in school (De Bruyn et al. 2003; Heaven and Ciarrochi 2008; Costa and McCrae 1988). Other studies have also shown that parents play an important role in framing their child's approach to learning (Papaioannou et al. 2008). For example, the results of Gonzalez-Pienda et al. (2002) indicate that parent involvement predicts child academic achievement indirectly via the child's academic self-concept and self-esteem. When parents helped their child to attribute their academic success to their skill and effort (versus chance), this had a direct positive effect on academic self-concept and self-esteem which, in turn, predicted academic achievement.

While the beneficial effects of authoritative parenting have been studied since the 1970 's, in this paper we investigate a new construct arising from the contemporary field of positive psychology, that of strength-based parenting (SBP). SBP is a style of parenting characterized by knowledge and encouragement of a child's strengths (Waters 2015a, b) and of parents using their own strengths in the parental role (Waters and Sun 2016).

A strength is considered to be any virtuous capacity, characteristic, or process that is persistently experienced as energizing and authentic by the individual (Govindji and Linley 2007; Sheldon and King 2001). Knowing and using one's strengths is significantly related to a host of youth wellbeing indicators, such as positive coping in child samples (Waters 2015a, b) as well as subjective wellbeing, self-esteem, self-efficacy, and life satisfaction in adolescent and young college students (Allan and Duffy 2014; Douglass and Duffy 2015; Jach et al. 2017; Proctor et al. 2011a; Suldo et al. 2014; Waters 2015a, b).

In a recent study examining wellbeing in high school students, Waters $(2015 \mathrm{a}, \mathrm{b})$ found that strength-based parenting (SBP) added significant variance above and beyond authoritative parenting to teenager life satisfaction. She suggested that SBP adds something extra to the warmth and boundaries provided through authoritative parenting because it creates a "positive filter" (p. 691) that alters the way a student engages with the world. Furthermore, by intentionally connecting a child with their strengths, SBP assists the child to grow their 
talents and positive qualities, which are then used as inner resources and energy reserves (as using strengths builds energy and intrinsic motivation) that may help the child to persevere toward long-term goals both in- and outside of school. While this theory indicates a clear distinction between SBP and authoritative parenting, studies have yet to test for the discriminant validity of SBP measures from other parenting styles, such as autonomygranting and responsive parenting. The current study aims to address this gap.

To date, no study has considered the effects that SBP may have on engagement and perseverance. However, given that SBP predicts strengths use in students (Jach et al. 2017) which, in turn, has been found to influence student engagement (Seligman et al. 2009; Madden et al. 2011) and potentially also student perseverance, it is theoretically plausible that SBP could have an effect on student engagement and perseverance by encouraging greater identification and use of strengths. Furthermore, as SBP has already been found to positively impact several aspects of student wellbeing (e.g., life satisfaction, positive affect, and subjective wellbeing), it is reasonable to infer that it may also affect other aspects of wellbeing such as engagement and perseverance.

As such, we predict SBP will indirectly influence student academic achievement by enhancing levels of engagement (by creating a positive filter) and perseverance (by building up resources and energy reserves). These relationships are outlined in Fig. 1 below. We also predict that the measure of SBP will have discriminant validity from two other well-established parental styles, namely responsiveness and autonomy-granting (which comprise authoritative parenting).

\subsection{Aims and Hypotheses}

We make the following hypotheses concerning this study:

1. The SBP measure will show discriminant validity from two other established parenting styles: responsiveness parenting and autonomy-granting parenting. ${ }^{1}$

2. There will be an association between SBP and (a) engagement, (b) perseverance, and (c) academic achievement

3. There will be an association between academic achievement and (a) perseverance and (b) engagement;

4. Perseverance and engagement will mediate the relationship between SBP and academic achievement.

\section{Method}

\subsection{Participants and Procedure}

The student sample was drawn from a large, public secondary school in Melbourne, Australia, in an average/middle socio-economic region $\left(N=741, M_{\text {age }}=13.70, S D_{\text {age }}=1.33\right.$; range $11-20 ; 50 \%$ female). The recruitment procedures of students in this study complied

\footnotetext{
${ }^{1}$ While only an initial test of psychometric discrimination, based on collegiate feedback it was deemed important to test whether SBP has unique characteristics from other known adaptive parenting styles. As the confirmatory sample with academic outcomes was limited, incremental validity tests were not undertaken.
} 
with the National Statement on Ethical Conduct in Human Research and were approved by the University's Human Research Ethics Committee.

At the start of term two students completed a self-report survey that assessed their ratings of SBP, engagement and perseverance. Three months later, at the end of term two, the mid-year academic grades for each student across all classes were given to the researchers by the school. Student grades were then inputted into the baseline dataset and matched to each student's SBP, engagement, and perseverance score.

We preregistered our initial hypotheses on the Open Science Framework, and the preregistration can be found here: https://osf.io/mqkju/. To test the study hypothesis according to our pre-registration of this study we randomly assigned students to either an exploratory sample (one quarter of the total data; $n=185$ ) or the confirmatory sample (three quarters of the sample; $n=556$ ). Analyses reported here were completed in the confirmatory sample.

Within the confirmatory sample, the school was only able to provide data concerning student grades for 388 participants. As such it was important to test whether these two groups, i.e., the students for whom we received academic grades $(n=388)$ and the remainder of the confirmatory sample $(n=168)$, differed on baseline measures of SBP, engagement, and perseverance. Multi-group comparison in SEM confirmed invariance in both the factor loadings and latent means for these measures across both sub-samples, indicating no differences in the variables of interest in the sample for whom we obtained academic outcome data (see supplementary materials, Tables S6-7; Byrne 2013; Cheung and Rensvold 2002).

\section{Measures}

\subsection{Strength-Based Parenting}

The SBP scale was originally created by Waters $(2015 \mathrm{a}, \mathrm{b})$ and was later adapted by Waters with a group of her colleagues in Jach et al. (2017) to comprise a 14-item scale with two sub-scales: SBP-knowledge (7 items; e.g., "My parents see the things I do best" $\omega=.95,95 \%$ CI $[.94, .96]$ and SBP-use (7 items e.g., "My parents suggest I should use my strengths every day"; $\omega=.95,95 \%$ CI $[.95, .96]$. Questions were presented on a 7-point scale ranging from strongly disagree to neither agree nor disagree to strongly agree. In keeping with Govindji and Linley's (2007) two-factor model of strengths, Jach et al. (2017) found that a two-factor structure made up of knowledge and use was the best representation of the data, providing evidence for the internal validity of this measure. Consequently, in the SEM analyses used for the current study, SBP is presented as a second-order factor comprising SBP-knowledge and SBP-use.

\subsubsection{Engagement and Perseverance}

The 4-item measures for each of these constructs are drawn from the 20-item EPOCH Measure of Adolescent Wellbeing (Kern et al. 2016). Engagement reflects the level of psychological connection, such as absorption or interest, that an adolescent has for a given task (e.g., "I get completely absorbed in what I am doing", $\omega=.81,95 \%$ CI $[.78, .84]$ ). Meanwhile, perseverance describes the capacity to carry out plans and goals to completion (e.g., "I keep at my schoolwork until I am done with it", $\omega=.83,95 \%$ CI $[.80, .86]$ ). Both 
scales are anchored on a 7-point scale from strongly disagree to neither agree nor disagree to strongly agree. Kern et al. (2016) found that these measures displayed good reliability, as well as evidence of convergent, discriminant, and predictive validity. As evidenced by the item wording, while engagement and perseverance are construed here as components of a broader construct of wellbeing, both sub-scales are targeted toward schooling.

\subsection{Academic Achievement}

Three months after the collection of student self-report measures for SBP, engagement and perseverance, the school provided the researchers with individual numerical student marks for each class taken that semester. Results were on a scale from 0 to 100 , and the averages of the marks earned across each class were calculated for each student in that semester.

There are two questions that one may ask about this operationalization of academic achievement: (1) is creating a composite measure of student grades a valid approach to take, given that students may perform well in one subject and poorly in another; and (2) is a measure of school grades a valid way to measure student achievement more broadly, given that tests are specific to the school and could be set at a higher or lower level than students are given in other schools?

To address the first concern, we classified grades according to four academic categories: Art/Music, Humanities, Science, and Other. We then investigated the correlations between participant scores for each of the four academic areas and found that they were substantial (Supplementary Material Table 1), varying between $r=.38$ (science and art/music) and $r=.71$ (science and humanities), suggesting that when students scored highly in one academic area, they were also likely to score highly in the others. Next, a factor analysis was undertaken on these variables, and the vast majority of tests (Velicer minimum average partial test, very simple structure, scree plot, Eigenvalues $<1$ ) indicated that a single academic factor was the optimal structure of the data (supplementary materials, Tables S1-2, Figure S1). These findings lend evidence of convergent validity of our use of an average mark to describe student achievement. They are also in line with the grade and mark averages used as a common method to assess academic achievement by past researchers (Cohen 1984; De Bruyn et al. 2003; Duckworth et al. 2007; Komarraju et al. 2011; Marques et al. 2011).

Next, to investigate the second concern and test the external validity of this measure in our own sample, we considered the school grades obtained for the semester alongside the results obtained by a nationwide standardized test, the Progressive Achievement Test (PAT). We obtained PAT math and English scores for a subset of participants dating from 2014 to 2016, and assessed the correlations between these measures and the average of student grades. Correlations between average school grades and PAT measures (Supplementary Material Table 2) were substantial, varying between $r=.53$ and $r=.68$. These results indicate that school grades are effective at representing the results that would be obtained in a standardized measure of achievement in secondary school students.

\subsection{Parental Styles}

Autonomy-granting parenting and responsive parenting styles were assessed using the parental styles inventory II (PSI-II; Darling and Toyokawa 1997), which has previously demonstrated internal consistency, convergent and discriminant validity, and adaptive relationships with a range of indicators for adolescent wellbeing and functioning, including at school (Darling and Toyokawa 1997). The original scale targets perceptions of mothers 
and fathers separately with each item being completed twice in reference to each parent, but due to extensive length of the existing survey battery in the present study items were reworded to target the generic "parents" and completed only once. Two sub-scales were of interest, both containing five items. The autonomy-granting (PSI-A; e.g. "My parents believe I have a right to my own point of view") and responsiveness (PSI-R; e.g. "My parents spend time just talking to me") sub-scales showed acceptable reliability in the current study: PSI-R $(\omega=.7995 \%$ CI $[.75, .82])$ and PSI-A $(\omega=.73,95 \%$ CI $[.69, .76])$.

\subsubsection{Analysis Plan}

Data cleaning was undertaken using SPSS and Excel. Discriminant validity and multigroup SEM comparisons were undertaken in AMOS V. 22. Descriptive and inferential analyses were then undertaken using $\mathrm{R}$ (version 3.3.1). Within $\mathrm{R}$, the lavaan package (Rosseel 2012) was used for structural equation modeling.

\section{Results}

\subsection{Discriminant Validity: Testing Hypothesis One}

To determine whether SBP is statistically distinguishable from two other well-known parenting styles - autonomy-granting and responsiveness- the PSI-R and PSI-A were entered into a confirmatory factor analysis (CFA) together with the SBP scale. Tests of discriminant validity were then undertaken on the entire sample $(N=739)$. Fit indices and a model comparison statistic were examined across nested models in which the second-order SBP factor was free to correlate with the PSI-R and PSI-A sub-scale factors, and models in which this correlation was constrained to one (Bagozzi et al. 1991; note variances of both factors were set to 1). If model fit is significantly worse in the constrained model, it suggests that discriminant validity holds for the SBP measure. Results are presented in Table 1.

Table 1 Nested models testing discriminant validity of SBP from PSI-R and PSI-A

\begin{tabular}{|c|c|c|c|c|c|c|}
\hline Model & $\Psi$ & $\chi^{2}(\mathrm{df})$ & RMSEA & SRMR & CFI & AIC \\
\hline \multicolumn{7}{|l|}{ SBP and PSI-R } \\
\hline Unconstrained & .84 & 860.14 (149) & .07 & .03 & .95 & 942.14 \\
\hline Constrained & 1 & $1022.51(150)$ & .09 & .04 & .94 & 1102.52 \\
\hline \multicolumn{7}{|l|}{ SBP and PSI-A } \\
\hline Unconstrained & .70 & 752.89 (149) & .06 & .03 & .94 & 834.87 \\
\hline Constrained & 1 & $1142.03(150)$ & .10 & .05 & .93 & 1222.03 \\
\hline
\end{tabular}

$\Psi=$ correlation between the higher order SBP factor and the PSI sub-scale factor

RMSEA Root Mean square error of approximation, SRMR standardised root mean square residual, $C F I$ comparative fix index, AIC Aikake information criteria

All $p$ values $<.001$ for the $\chi^{2}$ test and $\Psi$ estimate. This analysis was undertaken using AMOS V. 22 using maximum likelihood estimation and using the complete sample size post list-wise deletion of two cases with missing data $(N=739)$ 
When free to correlate, SBP as a second-order latent factor was strongly related to both latent parental responsiveness $(\Psi=.84, p<.001)$ and autonomy-granting $(\Psi=.70$, $p<.001)$. Although highly correlated, SBP showed discriminant validity through a significant decrement in fit in the constrained models (CMIN = 389.16(1), $p<.001$ for PSI-A; CMIN $=162.40(1), p<.001$ for PSI-R). Despite the PSI-II's prior validation, an item factor loading in the PSI-A was below .30 (the reverse-scored item "My parents make most of the decisions about what I can or can't do", with a standardised loading of .16). Only one other PSI-A item had a standardised loading of $<.50$. As such, the discriminant validity test model was re-run after removing this very low loading item. Overall model fit improved but discriminant validity results did not change, with an identical freely estimated latent factor correlation $(\Psi=.70, p<.001)$ and a marginally smaller and still significant decrement in model fit when this correlation was constrained (CMIN $=378.83(1), p<.001)$. These results suggest that SBP is a distinct style of parenting that is related to, but separate from, autonomy-granting and responsiveness.

\subsection{Descriptive Statistics and Correlations}

Table 2 displays the means, standard deviations, and correlation matrix for all variables of interest. All correlations were statistically significant, and the strongest correlations were between perseverance and engagement. SBP demonstrated strong correlations with both engagement $(r=.35)$ and perseverance $(r=.45)$. Note that average school grades are significantly correlated with SBP $(r=.12, p=.017)$, although this correlation is weaker than the relationship between average school grades and engagement $(r=.19)$ and average school grades and perseverance $(r=.29)$.

\subsection{Structural Equation Modeling: Testing Hypotheses Two through Four}

To test the interrelationships outlined in Fig. 1, a structural equation model was used. The measurement model included robust standard errors and a Satorra-Bentler scaled test statistic as advised by Rosseel (2012). For the mediation analysis, we used 10,000 bootstrapped standard errors, as recommended by Hayes (2009). Academic achievement was negatively skewed, skew $=-.49$, with the Shapiro-Wilk statistic indicating a significant

Table 2 Zero-order correlations of observed variables

\begin{tabular}{llllll}
\hline Variable & $M$ & $S D$ & 1. & 2. & 3. \\
\hline 1. SBP & 5.17 & 1.38 & & & \\
2. Engagement & 4.84 & 1.25 & $\mathbf{. 3 5}$ & & \\
3. Perseverance & 4.87 & 1.26 & $\mathbf{. 4 5}$ & $\mathbf{. 5 0}$ & \\
4. Achievement & 60.98 & 16.82 & .12 & $\mathbf{. 1 9}$ & $\mathbf{. 2 9}$ \\
\hline
\end{tabular}

SBP Strength-based parenting

All correlations presented here are statistically significant. Correlations <.001 (Holm-Bonferroni-corrected for multiple comparisons) are highlighted in bold. This correlation matrix employs pairwise deletion: specifically, for all correlations including achievement, a sample of 388 is used; and for all correlations not including achievement, the full 556 sample is used. The Supplementary Material presents the correlation matrix using complete cases (i.e., the 388 participant sample), which displays similar or identical effect sizes 


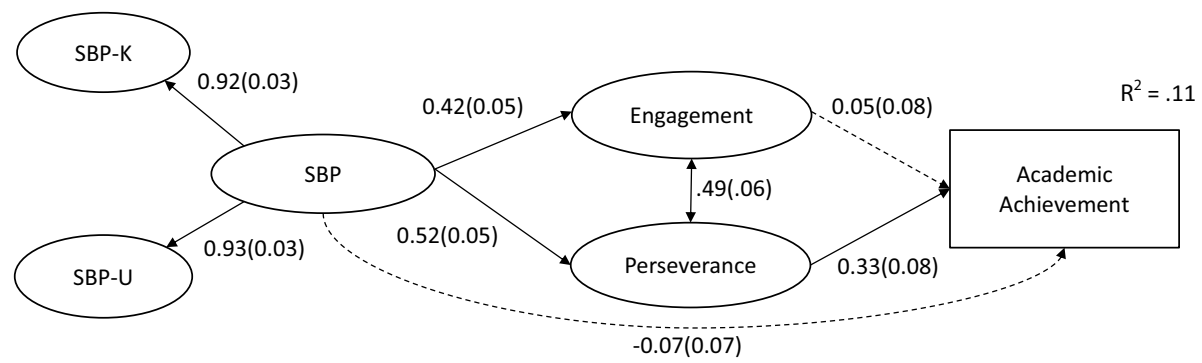

Fig. 2 The full mediation model. Values depict standardized $\beta$ weights, and values in parentheses depict the standard error of $\beta$. SBP strength-based parenting, SBP-K SBP-knowledge, SBP-U SBP-Use. Dotted lines indicate that a pathway is not statistically significant. Solid lines indicate significant pathways. All significant pathways are $p<.001$

departure from normality, $W=.98, p<.001$. Specifically, as can be seen in Table 1 , the mean of this variable was 60.98 (out of 100), indicating that the majority of scores were clustering higher than would be expected under the assumption of normality. Due to this violation of normality, we ensured that maximum likelihood method would be used to estimate the measurement and mediation models.

\subsubsection{Measurement Model}

Following the two-step approach to structural equation modeling (SEM) advocated by Anderson and Gerbing (1988), we initially examined the measurement model corresponding to our hypothesized constructs prior to commencing the full SEM. A CFA was undertaken with the latent constructs engagement, perseverance, and SBP (considered a secondorder latent construct comprised of SBP-Knowledge and SBP-Use) in which each of the latent variables were allowed to freely correlate with one other. Hu and Bentler (1999) suggest benchmarks of fit indices Comparative Fix Index (CFI) $\geq .95$, Root Mean Square Error of Approximation (RMSEA) $\leq .06$, and Standardized Root Mean Square Residual (SRMR) $\leq .08$. Our measurement model met these benchmarks, $\chi^{2}(204)=466.92, p<.001$, $\mathrm{CFI}=.96, \mathrm{RMSEA}=.05, \mathrm{SRMR}=.04$, indicating that it is appropriate to conduct the mediation analyses on these variables.

\subsubsection{Mediation Model}

A mediation analysis using Full Estimation Maximum Likelihood was undertaken to investigate our hypothesis that engagement and perseverance would mediate the relationship between SBP and academic achievement (as depicted in Fig. 1). For completeness, the Supplementary Material includes a version of this mediation in which listwise deletion was employed, to investigate the fit of different measures including only the 388 participants providing full academic and scale data. These supplementary results (Table S5; Figure S2) were identical, or very similar, to the results presented herein. In addition, factor loadings and latent mean estimates were compared between the group with $(n=388)$, and without $(n=168)$ academic results, which indicated no significant differences (Tables S6, S7).

The mediation analyses was a good fit to data across the different fit indices, $\chi^{2}(223)=789.09, p<.001, \mathrm{CFI}=.95, \mathrm{RMSEA}=.07, \mathrm{SRMR}=.04 ;$ and the model 
Table 3 Standardized beta coefficients $(\beta)$ of mediation analyses regarding SBP, engagement, perseverance, and academic achievement

\begin{tabular}{lcclr}
\hline Mediation model & $\beta$ & $S E$ & $Z$ & $p$ value \\
\hline E and P mediate SBP $\rightarrow$ grades & & & \\
Direct effect & -.07 & .07 & -1.10 & .271 \\
Indirect effect via E & .02 & .03 & .73 & .468 \\
Indirect effect via P & .17 & .05 & 3.78 & $<.001$ \\
Total effect & .12 & .06 & 2.15 & $<.031$ \\
\hline
\end{tabular}

$S B P$ Strength-based parenting, $E$ engagement, $P$ perseverance, $S E$ standard error of $\beta$

explained $11 \%$ of the variance in academic achievement (Fig. 2). Table 3 describes the coefficients and statistical significance of the mediation model. The mediation revealed a significant indirect effect of SBP on academic achievement, via perseverance, $\beta=.17$, $S E=.05, p<.001$. However, no significant indirect effect was observed through engagement, $\beta=.02, \mathrm{SE}=.03, p=.468$. There was no direct effect of SBP on academic achievement. Thus, the total effect of academic achievement was indirectly transmitted by the adolescents' level of perseverance: no direct effect of SBP was observed.

\section{Discussion}

In this paper, we have called for positive education to extend beyond the borders of the classroom and address the influence of parents on student wellbeing and academic achievement. The results of our study indicated that a strength-based approach to parenting, in which parents encourage their children to recognise and use their own strengths, is an enabler of academic success.

Before examining the relationships between SBP, student wellbeing, and student achievement, we investigated whether SBP was measuring a construct that is distinct from other parenting styles, specifically autonomy-granting and responsiveness. Supporting our hypothesis, our discriminant validity results indicated that SBP was indeed a unique construct from autonomy-granting and responsiveness. Interestingly, the teen ratings showed that parents who are strengths-based are also very often autonomy-granting and responsive. These interrelationships suggest that parenting styles are likely to occur in constellation with strengths-based approaches, and may indicate that other, complementary, positive parenting styles are mutually reinforcing.

Importantly, despite the interrelationships, the study also found that the three parenting styles were distinct.This aligns with the findings of Waters (2015b) who reported that authoritative parenting and SBP were significantly related but that each parenting style had a unique contribution to life satisfaction. More specifically, Waters (2015b) found that SBP predicted a larger, additional portion of variance in teenage life satisfaction over authoritative parenting.

Next, the current study investigated the interrelationships between SBP, engagement, perseverance, and academic achievement. Specifically, we hypothesized that the connection between SBP and academic achievement would be indirectly transmitted through the adolescents' levels of engagement and perseverance. Our results partially supported this hypothesis. Strong, significant correlations were observed between SBP and both engagement and perseverance, as well as between academic achievement and engagement and perseverance. When these variables were entered simultaneously into a double mediation 
SEM, SBP significantly predicted both engagement and perseverance. Although there was no direct effect observed from SBP to academic achievement, there was evidence of a significant indirect effect of SBP on academic achievement through the mediator perseverance. Unexpectedly, however, there was no evidence of an indirect effect through engagement.

First considering the pathway via perseverance, the evidence of mediation is aligned with a long history of research linking greater perseverance to higher grades (Barrick et al. 2001; Barrick and Mount 1991; Duckworth et al. 2007; Eskreis-Winkler et al. 2014; Trapmann et al. 2007). Until now, however, no study has considered the effect that SBP, or a strengths-focused approach in general, may have on perseverance. The current research addresses this gap by finding that SBP predicts greater adolescent perseverance, which in turn predicts higher academic achievement.

What mechanisms may be at play to produce these results? One potential account is that SBP allows the adolescent to understand and use their own strengths to a greater extent, and this more frequent use of strengths offers greater intrinsic motivation and energy (and, as will be discussed below, engagement), which then increases the perseverance in academic tasks, ultimately resulting in higher achievement.

Turning to engagement, the strong relationship found between SBP and engagement is consistent with the existing literature of strengths-based positive education interventions, which found that strengths identification and use led to greater engagement in adolescents (Madden et al. 2011; Seligman et al. 2009). Considering the full mediation, despite the substantial evidence that engagement relates to higher academic achievement (Ainley and Ainley 2011; Appleton et al. 2006; Bandura 1997; Clausen 1991; Dotterer and Lowe 2011; Dweck 2006; Hughes et al. 2008; Newmann 1992; Singh et al. 2002), we did not find a significant indirect effect of SBP to achievement through engagement.

However, considering the theoretical conceptualization of engagement put forward by Nakamura and Csikszentmihalyi (2014) these results may not be overly surprising. As discussed earlier in this paper, Nakamura and Csikszentmihalyi (2014) propose that engagement leads to achievement because of the connection that engagement has with perseverance. When individuals experience intense engagement (flow) in an activity, this encourages them to persevere at an activity because the flow experience is itself rewarding; this continued perseverance subsequently fosters skill development and achievement. According to this interpretation, then, engagement may be considered one antecedent of perseverance. This intriguing prospect would suggest that engagement remains an important component in the relationship between SBP and academic achievement, but that its effect on student achievement is generated by virtue of engagement's impact on perseverance.

\subsection{Advantages, Limitations, and Future Directions}

A key advantage of our study is the inclusion of an objective measure of academic achievement (i.e., school grades). By using actual school grades, rather than a self- or teacherreport of achievement, we avoid the possibility of common method bias where variance is attributed to the method of measurement rather than the constructs measured (Podsakoff et al. 2003), and also circumvent any instances of socially desirable responding in adolescents (i.e., reporting higher grades than they actually obtained) or bias in teachers (e.g., reporting higher scores for preferred students). In addition, we provide evidence of convergent and external validity of school grades, via factor analysis and comparison of 
this measure with a nationally normed measure of student achievement, the PAT scores. Finally, this variable was obtained 3 months after the initial survey assessing SBP, engagement, and perseverance, indicating that the way students were feeling earlier in the term about their parent's SBP, as well as their own levels of engagement and perseverance, predicted their subsequent results.

The two wellbeing variables used in our study, perseverance and engagement, are components of the EPOCH measure of adolescent wellbeing (Kern et al. 2016). In this study, we found that SBP predicts both of these measures. While the use of perseverance and engagement made sense in the current study where academic achievement was the outcome variable of interest, it would also be advantageous to see if SBP can also predict all components of EPOCH wellbeing (including optimism, connectedness, and happiness). This would provide evidence that a parenting style that focuses on strengths is comprehensively related to adolescent flourishing. This would additionally support Seligman's (2013) claim that strengths sit underneath all elements of his PERMA wellbeing model (upon which EPOCH is built).

Turning to consider the SBP scale, previous research has provided evidence of internal validity of its 2-factor structure (SBP-Knowledge and SBP-Use; Jach et al. 2017), a convergence in ratings across parent-teenage dyads, and incremental validity in predicting wellbeing over authoritative parenting (Waters 2015a, b). In this study, we demonstrated discriminant validity of the SBP from two other established parental style measures. Yet, further tests of discriminant and incremental validity for SBP against other constructs of parental style and self-knowledge would be beneficial. Additionally, the lay usage of the term strengths warrants further study. Although strengths has a well-established meaning in the positive psychology literature (Govindji and Linley 2007; Sheldon and King 2001), and the first item of the SBP scale defines strengths as "personality, abilities, talents, and skills", adolescents may still be likely to initially have a lay definition of the concept that differs from the intended definition of the scale. It is important to ascertain that adolescents have indeed connected these terms to the word strengths; otherwise this may limit their responses. Triangulation of the SBP construct, using qualitative methods-such as exploring strengths using inductive vignettes-may strengthen the scale and provide rich, nuanced examples of adolescent perceptions of SBP.

An additional limitation of this study is the smaller sub-sample for which grades were available. Although the full sample of 741 was used to test Hypothesis 1 (the discriminant validity of SBP), we split our sample into exploratory and confirmatory groups in accordance with best practice cross-validation procedures (Yarkoni and Westfall 2017) to test the remainder of our hypotheses; which left 556 for testing Hypotheses 2-4. Of this confirmatory group of 556 students we were only able to obtain academic data from 388 students. As there was no reason to believe that the data was not missing completely at random, all analyses in the manuscript body were undertaken using pairwise deletion. However, to ensure that our analyses were not subject to biased estimates due to unequal sample sizes, we conducted a series of checks (see Supplementary Material) using only complete cases (i.e., listwise deletion). The Supplementary Results for descriptive and SEM procedures were close or identical to the results presented in this manuscript body, making it likely that out results are unbiased. However, it would be beneficial to reproducing these relationships in future with larger samples to increase confidence in the results presented herein.

In this study, we have examined whether SBP increases engagement and perseverance, and grades. However, we have not addressed whether a volitional change toward a strength-based approach to parenting impacts the adolescents' levels of engagement and 
perseverance, and consequently their grades. Experimental and/or longitudinal designs would provide greater assurance in this direction of causation.

Finally, although parents are an undeniably important part of an adolescent's life, ecological theory suggests that multiple factors should be taken into account across many levels of an adolescent's environment. Thus, for a truly comprehensive view of positive education, it is necessary to look further than classroom and parental factors. Consider, for example, the broad range of variables that can be construed as having a likely impact on educational achievement or wellbeing in the socio-ecological framework. All of these variables may influence the development of the adolescent toward or away from wellbeing, and future research may wish to consider the many interrelationships between such factors in a comprehensive model of positive education.

\section{Conclusion}

In this study, we have called for positive education to take an socio-ecological approach, considering the many interweaving systems that produce youth wellbeing. Beyond the boundaries of the school system, this study indicates that parents can play a crucial role in promoting wellbeing and academic achievement in their children. We found that a strengthbased approach to parenting predicts perseverance and engagement, and that perseverance is one mechanism linking SBP to academic achievement. While preliminary, these results indicate SBP may be an important factor for schools to address in boosting student wellbeing and academic achievement.

\section{Compliance with Ethical Standards}

Conflict of interest The lead author is due to launch a book on strength-based parenting in 2017 and has been an invited Keynote speaker on this topic at the 2nd Positive Education Schools Association Conference (pro-bono), the Festival of Positive Education (pro-bono) and the 3rd Canadian Positive Psychology Conference, (speaker honorarium). The lead author is co-founder of The Strengths Exchange, a website offering free strength-based resources and tools to parents (http://www.the-strengths-exchange.com.au).

Open Access This article is distributed under the terms of the Creative Commons Attribution 4.0 International License (http://creativecommons.org/licenses/by/4.0/), which permits unrestricted use, distribution, and reproduction in any medium, provided you give appropriate credit to the original author(s) and the source, provide a link to the Creative Commons license, and indicate if changes were made.

\section{References}

Ainley, M., \& Ainley, J. (2011). Student engagement with science in early adolescence: The contribution of enjoyment to students' continuing interest in learning about science. Contemporary Educational Psychology, 36(1), 4-12.

Alexander, K. L., Entwisle, D. R., \& Horsey, C. S. (1997). From first grade forward: Early foundations of high school dropout. Sociology of Education, 70(2), 87-107.

Allan, B. A., \& Duffy, R. D. (2014). Examining moderators of signature strengths use and well-being: Calling and signature strengths level. Journal of Happiness Studies, 15(2), 323-337.

Allen, K.-A., Vella-Brodrick, D., \& Waters, L. (2016). Fostering school belonging in secondary schools using a socio-ecological framework. The Educational and Developmental Psychologist, 33(1), 97-121. 
Anderson, J. C., \& Gerbing, D. W. (1988). Structural equation modeling in practice: A review and recommended two-step approach. Psychological Bulletin, 103(3), 411-423.

Appleton, J. J., Christenson, S. L., \& Furlong, M. J. (2008). Student engagement with school: Critical conceptual and methodological issues of the construct. Psychology in the Schools, 45(5), 369-386.

Appleton, J. J., Christenson, S. L., Kim, D., \& Reschly, A. L. (2006). Measuring cognitive and psychological engagement: Validation of the student engagement instrument. Journal of School Psychology, 44(5), 427-445.

Bagozzi, R. P., Yi, Y., \& Phillips, L. W. (1991). Assessing construct validity in organizational research. Administrative Science Quarterly, 36(3), 421-458.

Baker, J. A., Maupin, A. N., Gilman, R., Huebner, E., \& Furlong, M. J. (2009). School satisfaction and children's positive school adjustment. In R. Gilman, E. S. Huebner, \& M. J. Furlong (Eds.), Handbook of positive psychology in the schools (pp. 189-196). New York and London: Taylor and Francis.

Bandura, A. (1997). Self-efficacy: The exercise of control. New York: Freeman.

Barrick, M. R., \& Mount, M. K. (1991). The big five personality dimensions and job performance: A metaanalysis. Personnel Psychology, 44(1), 1-26.

Barrick, M. R., Mount, M. K., \& Judge, T. A. (2001). Personality and performance at the beginning of the new millennium: What do we know and where do we go next? International Journal of Selection and Assessment, 9(1-2), 9-30.

Bassi, M., Steca, P., Della Fave, A., \& Caprara, G. V. (2007). Academic self-efficacy beliefs and quality of experience in learning. Journal of Youth and Adolescence, 36, 301-312.

Battin-Pearson, S., Newcomb, M. D., Abbott, R. D., Hill, K. G., Catalano, R. F., \& Hawkins, J. D. (2000). Predictors of early high school dropout: A test of five theories. Journal of Educational Psychology, 92(3), 568-582.

Baumrind, D. (1991). The influence of parenting style on adolescent competence and substance use. The Journal of Early Adolescence, 11(1), 56-95.

Baumrind, D., \& Damon, W. (1989). Rearing competent children. In W. Damon (Ed.), Child development today and tomorrow (pp. 348-378). San Francisco: Jossey-Bass.

Bempechat, J., \& Shernoff, D. J. (2012). Parental influences on achievement motivation and student engagement. In S. L. Christenson, A. L. Reschly, \& C. Wylie (Eds.), Handbook of research on student engagement (pp. 315-342). New York: Springer.

Bloom, B. S. (1968). Learning for mastery. Instruction and curriculum. Regional education laboratory for the Carolinas and Virginia, topical papers and reprints, Number 1. Evaluation Comment, 1(2), $\mathrm{n} 2$.

Bronfenbrenner, U. (1977). Toward an experimental ecology of human development. American Psychologist, 32(7), 513-531.

Bronfenbrenner, U., \& Ceci, S. J. (1994). Nature-nuture reconceptualized in developmental perspective: A bioecological model. Psychological Review, 101(4), 568-586.

Byrne, B. M. (2013). Structural equation modeling with AMOS: Basic concepts, applications, and programming (2nd ed.)., Multivariate Applications Series Hoboken: Taylor and Francis.

Cheung, G. W., \& Rensvold, R. B. (2002). Evaluating goodness-of-fit indexes for testing measurement invariance. Structural Equation Modeling, 9(2), 233-255.

Christenson, S. L., Reschly, A. L., \& Wylie, C. (2012). Handbook of research on student engagement. New York: Springer.

Ciarrochi, J., Atkins, P. W., Hayes, L. L., Sahdra, B. K., \& Parker, P. (2016). Contextual positive psychology: Policy recommendations for implementing positive psychology into schools. Frontiers in Psychology, 7, 1-16.

Clausen, J. S. (1991). Adolescent competence and the shaping of the life course. American Journal of Sociology, 96(4), 805-842.

Cohen, P. A. (1984). College grades and adult achievement: A research synthesis. Research in Higher Education, 20(3), 281-293.

Costa, P. T., \& McCrae, R. R. (1988). Personality in adulthood: A six-year longitudinal study of self-reports and spouse ratings on the NEO Personality Inventory. Journal of Personality and Social Psychology, 54(5), 853-863.

Csikszentmihalyi, M., Rathunde, K., \& Whalen, S. (1993). Talented teenagers: The roots of success and failure. Cambridge, England: Cambridge University Press.

Csikszentmihalyi, M., \& Seligman, M. E. (2000). Positive psychology: An introduction. American Psychologist, 55(1), 5-14.

Darling, N., \& Toyokawa, T. (1997). Construction and validation of the Parenting Style Inventory II (PSIII). Pennsylvania: The Pennsylvania State University, Department of Human Development and Family Studies. 
De Bruyn, E. H., Deković, M., \& Meijnen, G. W. (2003). Parenting, goal orientations, classroom behavior, and school success in early adolescence. Journal of Applied Developmental Psychology, 24(4), 393-412.

Della Fave, A., \& Massimini, F. (2005). The investigation of optimal experience and apathy: Developmental and psychosocial implications. European Psychologist, 10, 264-274.

DeYoung, C. G., Quilty, L. C., \& Peterson, J. B. (2007). Between facets and domains: 10 aspects of the big five. Journal of Personality and Social Psychology, 93(5), 880-896.

Dotterer, A. M., \& Lowe, K. (2011). Classroom context, school engagement, and academic achievement in early adolescence. Journal of Youth and Adolescence, 40(12), 1649-1660.

Douglass, R. P., \& Duffy, R. D. (2015). Strengths use and life satisfaction: A moderated mediation approach. Journal of Happiness Studies, 16(3), 619-632.

Duckworth, A. L., Kirby, T. A., Tsukayama, E., Berstein, H., \& Ericsson, K. A. (2011). Deliberate practice spells success why grittier competitors triumph at the national spelling bee. Social Psychological and Personality Science, 2(2), 174-181.

Duckworth, A. L., Peterson, C., Matthews, M. D., \& Kelly, D. R. (2007). Grit: Perseverance and passion for long-term goals. Journal of Personality and Social Psychology, 92(6), 1087-1101.

Durlak, J. A., Weissberg, R. P., Dymnicki, A. B., Taylor, R. D., \& Schellinger, K. B. (2011). The impact of enhancing students' social and emotional learning: A meta-analysis of school-based universal interventions. Child Development, 82(1), 405-432.

Dweck, C. (2006). Mindset: The new psychology of success. New York: Random House.

Eskreis-Winkler, L., Duckworth, A., Shulman, E., \& Beal, S. (2014). The grit effect: Predicting retention in the military, the workplace, school and marriage. Frontiers in Psychology, 5, 36.

Finn, J. D. (1989). Withdrawing from school. Review of Educational Research, 59(2), 117-142.

Forgeard, M. J., Jayawickreme, E., Kern, M. L., \& Seligman, M. E. (2011). Doing the right thing: Measuring wellbeing for public policy. International Journal of Wellbeing, 1(1), 79-106.

Frey, B. S., \& Stutzer, A. (2010). Happiness and public choice. Public Choice, 144(3-4), 557-573.

Gonzalez-Pienda, J. A., Nunez, J. C., Gonzalez-Pumariega, S., Alvarez, L., Roces, C., \& Garcia, M. (2002). A structural equation model of parental involvement, motivational and aptitudinal characteristics, and academic achievement. The Journal of Experimental Education, 70(3), 257-287.

Govindji, R., \& Linley, P. A. (2007). Strengths use, self-concordance and well-being: Implications for strengths coaching and coaching psychologists. International Coaching Psychology Review, 2(2), 143-153.

Hayes, A. F. (2009). Beyond Baron and Kenny: Statistical mediation analysis in the new millennium. Communication Monographs, 76(4), 408-420.

Heaven, P., \& Ciarrochi, J. (2008). Parental styles, gender and the development of hope and self-esteem. European Journal of Personality, 22(8), 707-724.

Hu, L. T., \& Bentler, P. M. (1999). Cutoff criteria for fit indexes in covariance structure analysis: Conventional criteria versus new alternatives. Structural Equation Modeling, 6(1), 1-55.

Hudson, N. W., \& Fraley, R. C. (2015). Volitional personality trait change: Can people choose to change their personality traits? Journal of Personality and Social Psychology, 109(3), 490-502.

Hughes, J. N., Luo, W., Kwok, O. M., \& Loyd, L. K. (2008). Teacher-student support, effortful engagement, and achievement: A 3-year longitudinal study. Journal of Educational Psychology, 100(1), 1-14.

Huppert, F. A., \& Johnson, D. M. (2010). A controlled trial of mindfulness training in schools: The importance of practice for an impact on well-being. The Journal of Positive Psychology, 5(4), 264-274.

Jach, H. K., Sun, J., Loton, D., Chin, T. C., \& Waters, L. (2017). Strengths and subjective wellbeing in adolescence: strength-based parenting and the moderating effect of mindset. Journal of Happiness Studies. https://doi.org/10.1007/s10902-016-9841-y.

Kern, M. L., Benson, L., Steinberg, E. A., \& Steinberg, L. (2016). The EPOCH measure of adolescent well-being. Psychological Assessment, 28(5), 586-597.

Kern, M. L., Waters, L. E., Adler, A., \& White, M. A. (2015). A multidimensional approach to measuring well-being in students: Application of the PERMA framework. The Journal of Positive Psychology, 10(3), 262-271.

Keyes, C. L. (2007). Promoting and protecting mental health as flourishing: A complementary strategy for improving national mental health. American Psychologist, 62(2), 95-108.

Komarraju, M., Karau, S. J., Schmeck, R. R., \& Avdic, A. (2011). The big five personality traits, learning styles, and academic achievement. Personality and Individual Differences, 51(4), 472-477.

Lamborn, S. D., Brown, B. B., Mounts, N. S., \& Steinberg, L. (1992a). Putting school in perspective: The influence of family, peers, extracurricular participation, and part-time work on academic 
engagement. In F. M. Newmann (Ed.), Student engagement and achievement in American secondary schools (pp. 153-181). New York: Teachers College Press.

Lamborn, S. D., Mounts, N. S., Steinberg, L., \& Dornbusch, S. M. (1991). Patterns of competence and adjustment among adolescents from authoritative, authoritarian, indulgent, and neglectful families. Child Development, 62(5), 1049-1065.

Lamborn, S. D., Newmann, F., \& Wehlage, G. (1992b). The significance and sources of student engagement. In F. M. Newmann (Ed.), Student engagement and achievement in American secondary schools (pp. 11-39). New York: Teachers College Press.

Larson, R. W., \& Rusk, N. (2010). Intrinsic motivation and positive development. Advances in Child Development and Behavior, 41, 89-130.

Lerner, J. V., Phelps, E., Forman, Y. E., \& Bowers, E. P. (2009). Positive youth development. In R. M. Lerner \& L. Steinberg (Eds.), Handbook of adolescent psychology. https://doi.org/10.1002/97804 70479193.adlpsy001016.

Linley, P. A., Nielsen, K. M., Gillett, R., \& Biswas-Diener, R. (2010). Using signature strengths in pursuit of goals: Effects on goal progress, need satisfaction, and well-being, and implications for coaching psychologists. International Coaching Psychology Review, 5(1), 6-15.

Ma, X., Shen, J., Krenn, H. Y., Hu, S., \& Yuan, J. (2016). A meta-analysis of the relationship between learning outcomes and parental involvement during early childhood education and early elementary education. Educational Psychology Review, 28(4), 771-801.

Madden, W., Green, S., \& Grant, A. M. (2011). A pilot study evaluating strengths-based coaching for primary school students: Enhancing engagement and hope. International Coaching Psychology Review, 6(1), 71-83.

Marques, S. C., Pais-Ribeiro, J., \& Lopez, S. J. (2011). The role of positive psychology constructs in predicting mental health and academic achievement in children and adolescents: A two-year longitudinal study. Journal of Happiness Studies, 12(6), 1049-1062.

Nakamura, J. (1988). Optimal experience and the uses of talent. In M. Csikszentmihalyi \& I. S. Csikszentmihalyi (Eds.), Optimal experience: Psychological studies of flow in consciousness (pp. 319326). New York: Cambridge University Press.

Nakamura, J., \& Csikszentmihalyi, M. (2014). The concept of flow. In Flow and the foundations of positive psychology (pp. 239-263). Springer.

Newmann, F. M. (1992). Student engagement and achievement in American secondary schools. New York: Teachers College Press.

Nidich, S., Mjasiri, S., Nidich, R., Rainforth, M., Grant, J., Valosek, L., et al. (2011). Academic achievement and transcendental meditation: A study with at-risk urban middle school students. Education, 131(3), 556-564.

Oppenheimer, M. F., Fialkov, C., Ecker, B., \& Portnoy, S. (2014). Teaching to strengths: Character education for urban middle school students. Journal of Research in Character Education, 10(2), 91-105.

Papaioannou, A. G., Ampatzoglou, G., Kalogiannis, P., \& Sagovits, A. (2008). Social agents, achievement goals, satisfaction and academic achievement in youth sport. Psychology of Sport and Exercise, 9(2), 122-141.

Parks, A. C., \& Schueller, S. M. (2014). The Wiley Blackwell handbook of positive psychological interventions. Chichester, West Sussex : Wiley Blackwell.

Peterson, C., \& Seligman, M. P. (2004). Character strengths and virtues: A handbook and classification. New York: Oxford University Press.

Podsakoff, P. M., MacKenzie, S. B., Lee, J. Y., \& Podsakoff, N. P. (2003). Common method biases in behavioral research: A critical review of the literature and recommended remedies. Journal of Applied Psychology, 88(5), 879-903.

Proctor, C., Maltby, J., \& Linley, P. A. (2011a). Strengths use as a predictor of well-being and healthrelated quality of life. Journal of Happiness Studies, 12(1), 153-169.

Proctor, C., Tsukayama, E., Wood, A. M., Maltby, J., Eades, J. F., \& Linley, P. A. (2011b). Strengths gym: The impact of a character strengths-based intervention on the life satisfaction and well-being of adolescents. The Journal of Positive Psychology, 6(5), 377-388.

Roberts, B. W., Walton, K. E., \& Viechtbauer, W. (2006). Patterns of mean-level change in personality traits across the life course: A meta-analysis of longitudinal studies. Psychological Bulletin, 132(1), 1-25.

Robins, R. W., Fraley, R. C., Roberts, B. W., \& Trzesniewski, K. H. (2001). A longitudinal study of personality change in young adulthood. Journal of Personality, 69(4), 617-640.

Rosseel, Y. (2012). lavaan: An R package for structural equation modeling. Journal of Statistical Software, 48(2), 1-36. 
Seligman, M. P. (2013). Flourish: A visionary new understanding of happiness and well-being. New York: New York Atria.

Seligman, M. E., Ernst, R. M., Gillham, J., Reivich, K., \& Linkins, M. (2009). Positive education: Positive psychology and classroom interventions. Oxford Review of Education, 35(3), 293-311.

Shankland, R., \& Rosset, E. (2017). Review of brief school-based positive psychological interventions: A taster for teachers and educators. Educational Psychology Review, 29(2), 363-392.

Sheldon, K. M., \& King, L. (2001). Why positive psychology is necessary. American Psychologist, 56(3), 216-217.

Shernoff, D. J., Csikszentmihalyi, M., Shneider, B., \& Shernoff, E. S. (2003). Student engagement in high school classrooms from the perspective of flow theory. School Psychology Quarterly, 18(2), 158-169.

Shernoff, D. J., \& Hoogstra, L. (2001). Continuing motivation beyond the high school classroom. New Directions for Child and Adolescent Development, 2001(93), 73-88.

Singh, K., Granville, M., \& Dika, S. (2002). Mathematics and science achievement: Effects of motivation, interest, and academic engagement. The Journal of Educational Research, 95(6), 323-332.

Srivastava, S., John, O. P., Gosling, S. D., \& Potter, J. (2003). Development of personality in early and middle adulthood: Set like plaster or persistent change? Journal of Personality and Social Psychology, 84(5), 1041-1052.

Steinberg, L., Elmen, J. D., \& Mounts, N. S. (1989). Authoritative parenting, psychosocial maturity, and academic success among adolescents. Child Development, 60, 1424-1436.

Steinberg, L., Lamborn, S. D., Dornbusch, S. M., \& Darling, N. (1992). Impact of parenting practices on adolescent achievement: Authoritative parenting, school involvement, and encouragement to succeed. Child Development, 63(5), 1266-1281.

Suldo, S. M., Savage, J. A., \& Mercer, S. H. (2014). Increasing middle school students' life satisfaction: Efficacy of a positive psychology group intervention. Journal of Happiness Studies, 15(1), 19-42.

Suldo, S., Thalji, A., \& Ferron, J. (2011). Longitudinal academic outcomes predicted by early adolescents' subjective well-being, psychopathology, and mental health status yielded from a dual factor model. The Journal of Positive Psychology, 6(1), 17-30.

Trapmann, S., Hell, B., Hirn, J. O. W., \& Schuler, H. (2007). Meta-analysis of the relationship between the big five and academic success at university. Journal of Psychology, 215(2), 132-151.

Waters, L. (2011). A review of school-based positive psychology interventions. The Australian Educational and Developmental Psychologist, 28(02), 75-90.

Waters, L. (2015a). The relationship between strength-based parenting with children's stress levels and strength-based coping approaches. Psychology, 6(6), 689-698.

Waters, L. E. (2015b). Strength-based parenting and life satisfaction in teenagers. Advances in Social Sciences Research Journal, 2(11), 158-173.

Waters, L. (2017). Progressing positive education and creating visible wellbeing. In M. A. Warren \& S. I. Donaldson (Eds.), Scientific advances in positive psychology. Praeger: Santa Barbara, California.

Waters, L., Barsky, A., Ridd, A., \& Allen, K. (2015). Contemplative education: A systematic, evidencebased review of the effect of meditation interventions in schools. Educational Psychology Review, 27(1), 103-134.

Waters, L., \& Sun, J. (2016). Can a brief strength-based parenting intervention boost self-efficacy and positive emotions in parents? International Journal of Applied Positive Psychology, 1(1-3), 41-56.

Yarkoni, T., \& Westfall, J. (2017). Choosing prediction over explanation in psychology: Lessons from machine learning. Perspectives on Psychological Science, 12(6), 1100-1122. 